\title{
Detection of interlayered illite/smectite by means of XRD and hyperspectral techniques: advantages and disadvantages
}

\author{
FIORENZA DEON, FRANK VAN RUITENBEEK,
} CAMILLA MARCATELLI AND CAROLINE LIEVENS

University of Twente - Faculty of Geo-Information Science and Earth Observation (ITC)

Presenting Author: f.deon@utwente.nl

The correct interpretation of clay minerals is often challenging due to the natural occurrence of interlayered phases. In this study we have investigated the occurrence of interlayered illite/smectite (I/S) in one rock sample from Rodalquilar, Spain. Previous studies on these rocks evidenced the occurrence of interlayered I/S via spectroscopic methods but these results were not confirmed until now with X-ray powder diffraction (XRD). This work offers for the first time a precise determination of the $\mathrm{I} / \mathrm{S}$ interlayering occurrence in the Rodalquilar samples conducted on the extracted clay fraction by means of XRD. Moreover the XRD results were compared with hyperspectral techniques applied on the same sample. We highlight the advantages and disadvantages of both applications when investigating challenging phases with interlayered structures. Moreover, a correct determination of the I/S interlayered phases along with clays swelling properties plays a crucial role in planning important geo-engineering projects 